\title{
MAPPING A TRANSFORMATION FROM A TRADITIONAL TO AN ENTREPRENEURIAl ORGANiSATION: A SOUTH AFricAn CASE
}

Authors:

Septimus Serfontein ${ }^{1}$

Johan S. Basson

Johann Burden ${ }^{1}$

\section{Affiliations:}

${ }^{1}$ Department of Human Resource Management,

University of Pretoria,

South Africa

\section{Correspondence to:}

Johann Burden

e-mail:

johann.burden@absamail. co.za

\section{Postal address:}

PO Box 524, Auckland Park, 2006, South Africa

Keywords:

grounded theory; organisational change;

organisational

transformation; case study approach; South African manufacturing company

\section{Dates:}

Received 24 July 2008

Accepted: 20 Mar. 2009

Published: 21 May 2009

How to cite this article: Serfontein, S., Basson, J.S., \& Burden, J. (2009). Mapping a transformation from a traditional to an entrepreneurial organisation: A South African case. SA Journal of Human Resource Management/SA Tydskrif vir Menslikehulpbronbestuur, 7(1), Art. \#155, 14 pages. DOI: 10.4102/sajhrm.v7i1.155

\section{This article is available} at: http://www.sajhrm.co.za

(c) 2009. The Authors. Licensee: OpenJournals Publishing. This work is licensed under the Creative Commons Attribution License.

\begin{abstract}
This study conceptualises the transformation of a company within a corporate environment after facing a crisis precipitated by several internal and external factors. A modernist qualitative research methodology was followed in order to understand transformational change as a phenomenon and to establish a set of principles practitioners can apply. Multiple data sources were used and the case study approach was applied to capture and interpret the emergent principles of the change process during the transformation. Grounded theory was used in the analysis of data. The result was a high-performance company that meets the criteria of an entrepreneurial unit in a corporate environment. The study provides practical guidelines for the transformation of a company and the implementation of factors such as strategy, the redesign of structures, organisational culture, leadership and communication.
\end{abstract}

\section{INTRODUCTION}

Pettigrew, Woodman and Cameron (2001) refer to the relative youth and interdisciplinary nature of organisational change and development, but state that the real challenge is to 'develop knowledge in the image of science while also contributing to practice and policy making' (p. 697).

Several writers have acknowledged that context and action are inseparable, that theories of change ought to explain continuity and that time must be an essential part of investigations of change if processes are to be uncovered (Greenwood \& Hinings, 1996; Van de Ven, Angle \& Poole, 1989).

On the other hand, the field of organisational change is not mature enough as yet to understand the dynamics and effects of time, process, discontinuity and context (Pettigrew et al., 2001). They state a need to search for general patterns of change, but in such a search more focus is required on several interconnected analytical issues, inter alia:

- Time, history, process and action

- The link between change processes and organisational performance outcomes

- The partnerships between scholars and practitioners in studying organisational change

Time, processes and action: In the context of organisational change, events and chronologies must be identified to use as stepping stones in the search for patterns and structures. This will enable the researcher to identify patterns in the process of change and will catch reality in flight. Pettigrew et al. (2001) believe it is safe to assume that the past is alive in the present and may be shaping the emerging future.

Change processes and organisational performance outcomes: According to Pettigrew, Woodman \& Cameron (2001), more clarity must be obtained on why and how certain organisations consistently perform better than others. Researchers have to seek the link between change capacity and actions towards better organisational performance and the dynamic and holistic appreciation of both processes and outcomes. The advantage is clear: Firstly, the outcome provides a focal point for the whole investigation, particularly when the process involves the collection and analysis of data over a long period. Secondly, there is the possibility of exploring how and why variations in context and process influence variability in observed performance outcomes.

Partnerships of scholars and practitioners: Pettigrew et al. (2001) believe that it is recognised that knowledge derives not only from individual thought, but from collective processes of networking and interpersonal communication. This statement particularly refers to the key role players in organisational change, namely scholars and practitioners. Partnership between these role players is vital.

\section{The research challenge}

How does a company in a newly formed merger, experiencing the pain of a crisis brought about by cultural differences, diminishing profits and internal organisational turmoil transform itself into a highperforming entrepreneurial unit in a larger corporate structure? After a successful transformation, the company explored by this research, although controlling only 30\% of the group's international assets and utilising only $28 \%$ of the group's manpower, contributed almost $80 \%$ to the group's profits.

The change started in October 1997 when the company experienced the crisis in question. In 1997 the company was the South African subsidiary of a larger international company in the wax business. At that stage, it was hierarchically structured and bureaucratically controlled. Business decisions were made by the management board in Germany. Within five years, the company was transformed into a highly successful entrepreneurial unit within the existing corporate environment, displaying the requirements of corporate entrepreneurship as described by Thomson and McNamara (2001, p. 671). Individuals displayed entrepreneurship and teams were led by intrapreneurs, or corporate champions who promoted entrepreneurial behaviour. They proactively engaged in risky projects and new innovative administrative procedures and products and services were created that facilitated organisational renewal and growth. 


\section{Characteristics of a turbulent environment}

Environmental turbulences are characterised by perceived dynamism, hostility and complexity. Dynamism refers to changes that occur in an organisation's environment because of technological and market shifts. As a result of these shifts, organisations are pressurised to revise their technological assets and to build new capabilities or to risk failure (Covin \& Covin, 1990; Prahalad, 1999). Hostility results from unfavourable changes in the market through proliferation of rivals, shifts in the ways companies position themselves, adverse regulatory changes or increased government protectionist policies (Miller, 1983). Environmental hostility is linked to globalisation and the resultant intensity of competition in a particular industry and the distortion of a previous structural and competitive equilibrium (Nohria \& Garcia-Pont, 1991). Environmental complexity refers to the degree of homogeneity or heterogeneity among environmental elements (Robbins, 2003). This may result from the perceived interconnectedness of the different external forces that influence a company's operation. Uncertainty about the company's environment makes it difficult to plan ahead.

\section{Responses to environmental turbulence}

A well-known brand, industry knowledge, preferential access to distribution channels, proprietary physical assets and a robust patent portfolio are still of enormous value to ensuring loyal customers, but these advantages are slowly being undermined by environmental turbulence.

Organisations respond to turbulence in many different ways Popular responses involve outsourcing, leasing and renting, shorter product life cycles, more frequent buying and selling, more frequent changes in contracts, a switch from mechanical to process technologies, a change from manufacturing to service economies and from central to local control. Quick fixes are often characterised by convulsive reorganisations, colossal write-offs, downsizing and indiscriminate, across-the-board lay-offs (Senior \& Fleming, 2006). Downsizing is particularly appealing to companies that are deeply in debt (Fisher \& White, 2000). Large sample studies indicate that lay-off announcements generally have a negative effect on market-adjusted equity values (Franz Crawford \& Dwyer, 1998; Lee 1997). In an effort to cope with the many challenges of the business environment, companies also enter into joint ventures, alliances, mergers and acquisitions These are seen as ideal for managing risk and uncertain markets, sharing the cost of large-scale capital investments, and injecting a newfound entrepreneurial spirit into maturing businesses (Bamford, Ernst \& Fubini, 2004)

\section{Short-term gains}

Companies that engage in cost-cutting often end up with more problems than profits. Research published in US News and Report (1992) showed that downsizing, cost-cutting and quick fixes had initially caused a spurt in share price and performance. This was followed by a long, painful slide. The study does not deny the sometimes staggering short-term gains that can be made by downsizing and cost-cutting. What it does show is that downsizing is often tantamount to amputating assets, resulting in a medium-term reduction in performance. This viewpoint is upheld in several other studies (Hall, Rosenthal \& Wade, 1993; Mabert \& Schmenner, 1997)

\section{Success rate of alliances}

In 2001, Bamford et al. (2004) assessed the outcomes of more than 200 alliance announcements during the previous decade. They found a success rate of only $53 \%$. These failures were mainly ascribed to wrong strategies, incompatible partners, inequitable or unrealistic deals and weak management.

It therefore appears as if a company's ability to respond to environmental turbulence is not about handling a one-time crisis, rebounding from a setback or downsizing the workforce.
Even carefully deciding on what makes business sense at a particular point, such as entering into a contractual alliance, is no guarantee for success, unless the changes inherent to these strategic decisions are managed effectively.

\section{Organisational change}

Van Tonder (2004b) is of the opinion that change is a process which is dynamic, time-bound, and non-discrete, evident in a difference in the state and/or condition within a state of an entity (p.6).

Organisational change is no different from change in general. Van de Ven and Poole (1995, cited in Van Tonder, 2004c, p. 54) differentiate organisational change only through the addition of the term organisation, which contextualises the change.

Organisational change can therefore be seen as an initiative that alters critical organisational processes which, in turn influence individual behaviour, which subsequently impact on organisational outcomes (Porras \& Silvers, 1991).

\section{Organisational transformation}

To go beyond the process that defines organisational change, activities must be directed at the basic character of an organisation. Van Tonder (2004c) equates organisational transformation with second-order change, which is multi-dimensional, multilevel, qualitative, discontinuous and radical and involves a paradigmatic shift. Cummings and Worley $(2005$, p. 499) cite that the change goes far beyond improving the existing organisation or the status quo, but is rather concerned with a change in organisational assumptions about its functioning and how it relates to the environment. This implies that members perceive, think and behave differently at work.

Tuschman, Newman and Romanelli (1986) observe that transformational change occurs in response to at least three kinds of disruptions:

- Industry discontinuities

- Product life cycle shifts

- Internal company dynamics

These disruptions severely shock organisations and push them to alter business strategy, structure, systems and procedures.

Transformational change can be distinguished from other forms of organisational change in the following ways:

- Transformations entail significant shifts in corporate philosophy and values and in the numerous structures and organisational arrangements that shape members' behaviour. Not only is the magnitude of change greater 'but the change fundamentally alters the qualitative nature of the organisation' (Cummings \& Worley, 2005; Nut \& Backoff, 1997). Interventions revolve around culture change, self-design, organisational learning and knowledge management.

- Transformational change can be seen as a transfiguration from one state to another and the successive state of being (Hill \& Collis, 2000; Kilmann, 1995; Marshak, 1993). This signifies a change in an organisation's mode of existence and functioning (Van Tonder, 2004c). Transformational change involves reshaping the organisation's culture and design elements. These changes are characterised as systemic and revolutionary because the entire nature of the organisation is altered fundamentally (Hamel \& Välikangas, 2003; Van Tonder, 2004c). This view indicates that the impact of transformational change is at the organisational paradigm level.

- Transformational change is particularly pertinent to changing the different features of an organisation, such as structure, information systems, human resource practices and work design (Maijer, Tsui \& Hinings, 1993). These features need to be changed together and in a coordinated fashion so that 
they can mutually support one another and the new cultural views and assumptions (Miller \& Friesen, 1984).

- Transformational change can be distinguished from other types of strategic change by its attention to the people side of the organisation. Blumenthal and Haspeslagh (1994) emphasise sustainability of change through behavioural change, for which the measure of 'success' is the longterm financial success of the organisation. For change to be labelled transformational, a majority of individuals in an organisation must change their behaviour (Blumenthal \& Haspeslagh, 1994; King, 1997).

- Transformational change can be described as a totally new state of being out of the remaining of the old state - a new state that is unknown until it begins to take shape (Ackerman, 1986). Transformational change is therefore distinguished from other forms of change such as developmental change and transitional change.

- A key feature of organisational transformation is the active role of senior executives and line managers in all phases of the change process (Waldersee, 1997).

To conclude, transformational change is a far more comprehensive and complex concept of change. It is a form of change that could unfold quite rapidly to a point where the impact will be irreversible and evident in the organisation's character, form and appearance. This state and appearance could be quite different from the pretransformation state of the organisation (Van Tonder, 2004c).

\section{In pursuit of entrepreneurship}

The outcome of a transformation is often the emergence of numerous new organisational forms in an effort to ensure continuous strategic renewal (Chakravarthy \& Gargiulo, 1998). It appears as if these forms are distinguishable by two factors:

- An emphasis on bottom-up entrepreneurship

- Reliance on a cooperative network that allows these entrepreneurial units to share their competencies

Echols and Neck (1998) maintain that the best blueprint to survive in the dynamic environment of the 21st century is firstly, hiring and rewarding employees who demonstrate entrepreneurial behaviours and secondly, adopting structures that facilitate these behaviours. Contemporary business pressures are also forcing organisations to identify and place managers in entrepreneurial roles and emulate an entrepreneurial environment so that these managers may operate relatively free within the larger organisational structure. Luczkiw (2002) believes that entrepreneurial units will eventually replace most bureaucratic and hierarchical structures, and that these entrepreneurial units will emerge on the edge of existing structures.

A pertinent question is whether large companies can be entrepreneurial? The challenge to large companies is to encourage a sense of innovation, autonomy and entrepreneurship, despite the required structure and systems of the bureaucracy. Another challenge is to leverage their resource advantage while acting quickly, efficiently and effectively and to move faster than specialised, newer and smaller organisations (Figueroa \& Conceica, 2000).

It seems logical that the emergence of entrepreneurial units and the replacement of hierarchical structures must invariably also lead to a change in leadership. Changes in the workplace will demand another type of leadership. A flatter organisational hierarchy with its shrinking management ranks and less bureaucracy, coupled with the need for greater speed, better customer responsiveness and ongoing innovation, will require leaders who are visionaries, can solve problems, can make timely decisions and can accept risk (Fernald \& Solomon, 2001).

\section{Definition of the problem}

Organisations find themselves in a turbulent environment and respond to turbulence by engaging in different forms of change, including transformational change. Organisational change research illuminates the need to identify events and chronologies as stepping stones in these change interventions to establish patterns and structures. Coinciding with this, the requirement exists to find a clear, holistic link between change processes and organisational performance outcomes. This quest to map the process of change offers the challenge to generate knowledge collectively to the benefit of both practitioners and scholars (Pettigrew et al. 2001).

The research problem statement initially raised several research questions, viz.:

- What internal and external factors could trigger a transformation?

- What events, processes and patterns will surface chronologically during the transformation?

- How can scholars and practitioners utilise knowledge derived from the transformation in their respective performance domains?

The aim of the research was to develop a conceptual framework of events, processes and patterns over the duration of a transformation from a traditional, functionally structured organisation to an entrepreneurial unit within a corporate environment.

\section{RESEARCH DESIGN}

Three aspects are normally included in the research design, namely the research approach, the utilisation of a case study as a research strategy and the research methodology (Mouton \& Marais, 1988).

\section{Research approach}

Denzin and Lincoln (2000) describe qualitative research as a 'complex interconnected family of terms, concepts and assumptions' (p. 1048). In this section, the research paradigm selected by the authors will be defended. To further set the research foundation, the authors' ontological and epistemological beliefs are stated, which in turn set the criteria for the selection of the appropriate research strategy.

\section{Key scientific beliefs}

According to Mouton and Marais (1988, pp. 20-21), a researcher should be aware of his or her own metatheoretical values or beliefs or particular philosophical assumptions. These assumptions should not influence the way in which the research will be conducted, but can constitute an 'intellectual climate' for particular beliefs in the nature of a social reality that can impact the 'qualities of postulates'.

Ontological position: An ontological position concerns the researcher's views and the very nature and essence of a social reality. To test this principle, it is helpful to understand what the alternatives are, as Mason (2002) aptly describes.

The ontological perspective of the authors suggest that social reality is not only based on objective notions and cannot be controlled or predicted, but is also subjectively constituted. According to Schurink (2005), it is important for researchers to understand the impact that ontology has on the chosen research topic. The authors believe that the notion of transforming a traditional organisation to an entrepreneurial organisation is at best a subjective concept. Peoples' ideas, views, actions, reactions, interactions, social relations, social and cultural practices, rules and values reflect their experiences. They furthermore determined how these experiences and understanding brought about a change in peoples' perceptions, thinking and behaviour (Cummings \& Worley, 2005), how it contributed to fundamentally altering the company's assumptions about its functioning and relations with its environment (Cummings \& Worley, 2005, p. 499) and how it eventually changed the features of the company (Maijer et al.,1993). Ritchie and Lewis (2004, p. 21) 
refer to the importance of the researcher's interpretation because 'deeper insights can be obtained by synthesizing, interlocking and comparing the accounts of a number of respondents'. The research participants were therefore engaged in the study in a manner that involved them more deeply than would have been the case in research of the quantitative, positivist tradition. It was therefore critical for the researcher to obtain a 'thick description' from the respondents' perspective, while also contextualising this so as to be able to compare meaningfully the observations between respondents. This is also in line with the interpretive perspective, which is usually a feature associated with the qualitative research tradition, as discussed.

The authors, however, realise that context utilisation is not only an intellectual 'understanding', but that it is just as much a matter of maturity, judgement, common sense and emotional balance (Gummesson, 2000, p. 4). Neither academic research nor management experience is therefore enough. The personality of the scientist is still a key research instrument.

As a result of the aforementioned, the authors also believe that changes in the perception, thinking and behaviour of people in an organisation predispose them to successfully progress through a process of change, displaying distinct changes in behaviour as the process evolves from one phase to another.

Epistemological position: Epistemology refers to what might represent knowledge or evidence in the social world according to the researcher (Mason, 2002). A researcher's epistemology is literally his or her theory of knowledge, and should therefore consider the principles and rules by which decisions on social phenomena can be known, and how knowledge can be demonstrated. Epistemological questions should therefore direct the researcher in considering the philosophical issues involved, while carefully contemplating exactly what is acceptable evidence or knowledge of social phenomena to explain social reality (Mason, 2002, p. 16).

The authors accept that the choice of criteria used to assess the quality of research and consulting work is different and that the sourcing of the criteria they used to evaluate the research findings could have been different, as the researcher primarily worked with the consultant paradigm and not the scientific paradigm, particularly in the earlier stages of research (Gummesson, 2000).

In this regard, the authors believe that multiple unstructured data-gathering methods are necessary to capture the activities and experiences of people who are involved in a transformational process of changing a traditional organisation into an entrepreneurial one.

Given the aforementioned explication, the authors believe that the researcher was able to demonstrate that his ontological and epistemological positions are closely aligned to those of the qualitative, modernistic approach.

Choosing a modernist qualitative research approach: Denzin and Lincoln (2003) describe the emergence of qualitative research over several periods, or what they term historical 'moments'. Some common ground exists among these moments and is all still currently relevant in different research circumstances. Denzin and Lincoln state that the history of qualitative research is defined more by 'breaks and ruptures than by clear evolutionary, progressive movement from one stage to the next'(2003, p. 21). The first moment is defined as the traditional period, and existed from the early 20th century until just after the end of World War II. This period was followed by the second moment, namely the modernist age, which lasted until the 1970s. During this period, attempts were made to formalise methods and processes in qualitative research. During the latter stage of this period, Glaser and Strauss (1967) further formalised approaches to qualitative analysis to enhance the rigour of data collection and analysis. Strauss (1987) and Strauss and Corbin (1990) continued to elaborate on the fundamental principles underpinning this approach to qualitative research. According to Denzin (1988), the modernist paradigm is still a relevant research approach today.

In this study, a modernist qualitative research approach was deemed more appropriate because of the volume and complexity of the data and the desire to understand transformational change as a phenomenon. Reality had to be understood to discover meaning. Furthermore, the fact that the researcher was involved in the transformation (as consultant) and formed part of the object of investigation required the use of qualitative methods (Guba \& Lincoln, 1994, p. 108).

\section{Case study as a research strategy}

Yin (2003) describes the case study as a research strategy comprising a holistic method that covers the logic of design including the scope, data-collection methods, as well as specific approaches to the analysis of the data. Yin (2003) points out that the case study is firstly an empirical inquiry that seeks to understand present-day phenomena within a real world context, where the boundaries between the phenomena and the context are not clearly evident. Secondly, multiple data-collection and data-analysis methods are an important part of the definition, as a distinctive situation needs to be dealt with, in which there are many more variables of interest than data points that rely on multiple sources of evidence. This is in line with the researcher's epistemological position.

From the above, the authors placed the single case study, which the researcher had selected to use, in the inductive research tradition, specifically considering that theory will be built from research data and the application of methods as suggested by Bryman and Bell (2007, p. 64) and Carlile and Christensen (2005). These authors argue that a case study is also a vehicle for theory generation and theory testing.

The researcher followed a single exploratory and intrinsic case study method in describing and exploring employees' experiences regarding their understanding and implementation of a transformational process aimed at changing a traditional organisation into an entrepreneurial one. In this regard the authors recognise the usefulness of the case study method in capturing the emerging and changing properties during an organisational transformation (Barley, 1990; Stake, 2000). As a result of the aforementioned statement, case studies can also have the function of generating hypotheses and building theories (Eisenhardt, 1989).

\section{Research methodology}

The word 'methodology' in research is defined as 'the logic of implementing scientific methods in the study of reality' (Mouton \& Marais, 1988). The researcher considered the following components of research methodology:

- The research setting

- The way in which entrée was achieved

- The sampling methods employed

- Data-collection methods used

- The way in which the data were recorded and managed

- The analysis of the data

- Strategies used to ensure the quality of the research

- Reporting style followed

- Ethical considerations applied.

\section{Research setting}

The research was conducted in a South African subsidiary of a larger international company in the wax business. The total staff complement of 400 people was involved. Over a six-year period this number was gradually reduced to just over 300 . 


\section{Entrée and establishing researcher roles}

Access or entrée to the research setting is usually undertaken by obtaining permission from the highest levels of authority. This authority needs to vest in individuals who are able and willing to make the research setting accessible to the researcher and are referred to as 'gatekeepers' (Bogdan and Biklen 2003, pp. 7576)

In this particular case the researcher was appointed as a consultant by the management board in Germany in October 1997 to guide and facilitate an organisational transformation process in the South African subsidiary. From the beginning his intention was to record a detailed account of the process. As a consultant he brought with him experience gained over 25 years, working as an organisation development consultant and industrial psychologist. As the project evolved, the value of the work from a research perspective was realised. As he engaged in the research he was obliged to switch from the consultant paradigm to the scientific paradigm. However, critical consideration needs to be given to establishing a researcher role and the researcher's attitudes. The boundaries of this role require careful contemplation, definition and differentiation.

To counter the possibility of research bias as a result of the consulting role and to ensure that good quality of research was maintained, the researcher relied on multiple sources of data (Stake, 1995; Yin, 1994), establishing a chain of evidence (Soy, 1996) and having the draft case study report reviewed by key informants (Yin, 1984). The researcher was acutely aware of the criticism against the use of a single case (Tellis, 1997) and was particularly careful to avoid misrepresentation. He allowed for both triangulation of data sources and analytical perspectives in order to increase the accuracy of findings in the case and to offer viable alternative explanations, where required (Patton, 1999).

\section{Sampling}

In qualitative research, information-rich data needs to be collected that will yield thick descriptions. It was therefore important to decide how the sample was to be framed and developed to enable a draft protocol to be designed (Schurink, 2007).

Mason (2002) defines purposive sampling as the selection of groups or categories to study on the basis of their relevance to the research questions, the researcher's theoretical position and analytical framework, his or her analytical practice and, most importantly, the argument being developed. The aim was to collect data with a view of enabling theory to emerge as that data are simultaneously recorded, coded and analysed. This is part of a cyclical process that is repeated until theory emerges, and data saturation is reached.

The different roles in which the researcher operated (consultant and expert resource) necessitated that theoretical sampling be utilised in its purest form as the only sampling technique used in the research. The following participants were used:

- Management board

- Management team

- Project team

- A cross-section of employees as represented in the various focus groups

- Samples of the total work force

- Self-managing teams

- Leaders of business units.

The researcher was acutely aware during the sampling process not to be gender biased, which Babbie and Mouton (2004, pp. 37-38) refer to as critical feminism: standpoint epistemology.

\section{Data-collection methods}

The primary purpose of effective data collection is to ensure that the researcher's understanding of the problem is enriched as much as possible. A variety of data-collection techniques needs to be considered when undertaking qualitative research to ensure that information-rich data is collected (Patton, 1987).

Mason (2002) states that the researcher needs to be clear on the methodological implications of his or her choices. Qualitative research lends itself to methods of data generation that are sensitive to the social context, and are able to integrate different methods and sources of data, using techniques such as triangulation.

In this research the researcher relied on data sources such as one-on-one unstructured interviews, consultant reports, group interviews, observations, surveys, focus groups, strategic and operational plans, minutes of meetings, designs of workshops, designs of interventions and personal notes (field notes).

One-on-one unstructured interviews: According to Mason (2002), interviewing is the most widely used technique in the qualitative paradigm and he refers to two main typologies of qualitative interviewing, namely the in-depth interview and the structured interview. Mason suggests that the term unstructured interview is a misnomer, as no qualitative interview lacks structure completely.

Initially, pilot interviews were conducted and the interview guideline and content were modified as the change process evolved and more insights, experience and understanding were gained into transformation as a phenomenon.

Documents: According to Bryman and Bell, documents that reside within a research setting are important data objects, predominantly in qualitative research, that are 'waiting to be assembled and analysed' (2007, p. 553). Bryman and Bell (2007) draw another distinction, namely that of organisational documents, which are highly relevant to management research. The latter was extensively used, particularly at the start of the transformation and for the period when the new managing director (MD) championed the change effort.

Focus groups: The classical definition of a focus group was given by Smith in 1954 when he referred to the term group interviewing as being limited to those situations where the assembled group is small enough to permit genuine discussion among all its members' (cited in Breakwell, Hammond \& FifeSchaw, 2000, p. 304).

Focus group participants were selected to represent various levels and functions within the company. They were utilised in several roles, e.g. to analyse existing processes, to assess the impact of a particular intervention at shop floor level, to test the applicability of certain design principles and to perform redesign work. All these activities directly impacted on the final result.

Surveys: Survey samples can offer a very effective sample frame for a qualitative study (Ritchie \& Lewis, 2004). The authors state that 'although qualitative samples themselves are not designed to be statistically representative it can be useful for the sample frame from which they are selected to do so' (Ritchie \& Lewis, 2004 , p. 90). A survey must be seen as a rich source of data to support purposive sampling, but to be effective it has to meet the requirements of comprehensiveness, diversity and lack of bias.

In the study surveys were used to assess which values drove behaviour initially, but on several occasions during the implementation stages the researcher relied on surveys to monitor progress in regard to the entrenchment of values. Surveys were also successfully utilised to evaluate the organisation as an entrepreneurial business as experienced by employees, and they were also used a year later to answer the question of how sustainable the change was.

Given the fact that the total population was involved in the surveys, sample frames were not generated. The need for diversity was always stressed to prevent the researcher in 
his capacity as consultant from leaning towards contacting people who are thought likely to give a positive account. The survey population varied between $82 \%$ and $86 \%$ of the overall complement. The authors regard the percentage as realistic because of people on leave or ill on a particular day. All people on shift could not leave the operation, which necessitated several sittings during a particular day to administer questionnaires. The fact that a relationship existed between the project team/ consultant and the employees smoothed the way to participation in these surveys.

The choice of purposive selection criteria was influenced by the aim of the study, the research questions and relevant literature originating from other research. Criteria that were considered included age, gender, ethnic origin, regional location, employment activity and business unit.

The choice of variables differed from one survey to another. The primary criteria were those that the researcher considered most important to the subject and objectives of the survey (Ritchie \& Lewis, 2004).

\section{Recording of data}

Field notes and transcriptions of taped interviews are considered traditional means of recording data (Schurink, 2004, p. 11). The researcher extensively made use of field notes and applied transcriptions in a modified way.

Field notes: According to De Vos, Strydom, Fouché \& Delport (2005, p. 285), field notes are made by qualitative researchers of everything they see or hear. Schurink (2004, p. 12) believes that the successful outcome of a participant observation study in particular, but also other forms of qualitative research, are dependent on detailed, accurate and extensive field notes.

Field notes consist of two kinds of materials. The first kind is descriptive - to provide a verbal picture of the setting, people actions and conversations as observed. The second field note variety is reflective - capturing more of the observer's frame of mind, ideas and concerns. Both were performed using the consultant paradigm.

Because of the voluminous nature of the data collected, it was later organised into a comprehensive primary package. Data were edited, redundancies sorted out and parts were fitted together (this time using the scientific paradigm). The data were now ready for access chronologically, at a level beyond raw data. The case record contained 385 sources, covering the period August 1997 to September 2003.

The researcher compiled a project diary to capture the deployment of the study, used auto-ethnographical sketches describing his experiences and thoughts on the transformation process and memos in which he noted his ideas and insights on the meaning of the data.

Transcriptions of interviews: According to Bogdan and Biklen (2003, p. 124), it is important to transcribe sections on a tape that specifically address the concerns of the research. In this particular case the project was simply too comprehensive, too intense and too results-orientated to use the classic method of tape recording interviews and transcribing them. Credibility of the consultant was another consideration for not following this approach. This was particularly true for the start of the project, when a crisis climate prevailed.

Data were therefore noted as completely as possible during the interview, followed by a period of reflection and consolidation after the interview. Afterwards (usually on the same day) interview notes and observations were dictated and typed which amounts to a form of transcription.

\section{Data analysis}

Data analysis in the modernist paradigm began around the time of Descartes and involves gaining knowledge through a reliance on reason (Locke, 2003). Locke (2003) reiterates that the paradigm involves the utilisation of formal methods. Grounded theory fits into the later stage of the modernist phase of qualitative research.

Grounded theory, as an analytical framework, fits in with a modernistic and inductive approach. Grounded theory split into two camps, each subtly distinguished by its own ideographic procedures. Whereas Glaser (1978) stresses the interpretive, contextual and emergent nature of theory development, the late Strauss appears to have emphasised highly complex and systematic coding techniques. Strauss and Corbin (1990) exemplify this rupture with their presentation of multiple coding procedures such as open, axial and selective coding, and techniques of comparison that are now used to enhance analysis by intentional manipulation of data in a number of ways. Glaser (1978) only speaks of open and selective coding. Strauss (1987) believes that clarification of the process is achieved by distinguishing three stages of naming and comparing activity, as mentioned above.

The researcher decided to manually employ the techniques used by Strauss and Corbin (1990) because he required the coding procedure that their technique suggests in order to develop a procedure for analysing the transformational process. Grounded theory has been successfully applied to studies in organisational change and innovation (Carrero, Peiró \& Soloman, 2000; Lowe, 1995; Price, 1994).

Grounded theory and theory: Glaser and Strauss make much of the difference between substantive and formal theory:

By substantive theory we mean that theory developed for a substantive or empirical area of sociological inquiry, such as patient care, race relations, and professional education, delinquency, or research organizations. By formal theory, we mean that theory developed for a formal, or conceptual, area of sociological inquiry, such as stigma, deviant behaviour, formal organization, socialization ...

(Glaser \& Strauss, 1967, p. 32)

They view formal theory as the sociologist's (scientist's) goal. However, they insist that to be valid, formal theory must be developed from a substantive grounding in concrete social situations.

In organisation studies many theories are substantive; decision making and leadership being two instances. Substantive theories may even be developed for issues associated with working in virtual organisations or managing contingent workers. When reference is made to formal theory it usually refers to those areas of inquiry that operate at a high level of generality, such as systems theory, agency theory and contingency theory (Locke, 2003). The product of this study was the development of a conceptual framework (typology) for organisational transformation. The characteristics of this product are described in the section 'Definition of the conceptual framework'.

Execution of grounded theory: As already mentioned, the reseacher used many data-collection methods and relied on a multitude of data sources that posed a challenge to him regarding how to analyse the magnitude of information in a meaningful way. As consultant the reseacher was very close to the data for most of the period of the research. It is, however, important to note that the researcher was engaged in different relationships with the data at different times, which included direct involvement as a consultant at the beginning, indirect involvement as an expert resource to the Human Resource (HR) manager when the new MD championed the change, and in an objective role as a researcher after the decision to engage in a scientific study.

The researcher allowed the process to be concluded into a documented case study that reflected the integrated storyline of 
the transformational process from beginning to end. Thereafter, the researcher decided to analyse all the raw data, applying manual coding structures to identify the related concepts within this transformational process in accordance with the integrated storyline of the documented case study. The researcher commenced with open coding.

Open coding: Strauss and Corbin (1998, p. 101) define open coding as the analytic process through which concepts are identified and their properties and dimensions discovered in the data.

During open coding the data are broken down into discreet parts. These are then closely compared for similarities and differences, after which questions are asked about the phenomenon embedded in the data. In fact, grounded theory is often referred to in the literature as the constant comparative method of analysis (Glaser \& Strauss, 1967).

The researcher analysed consultant reports, focus group responses, minutes of meetings, workshop outcomes, personal notes, survey results and the transcripts of the personal interviews by breaking them into distinct units of meaning per line of text and then identifying key words or phrases of the phenomenon under investigation. He tried to establish a link between a passage of text of any length and some general theme related to transformation as a phenomenon.

Therefore, the theoretical concepts were set aside and a pure grounded theory approach was followed, that is, coding was used as the only means of establishing what the generated data revealed about the phenomenon.

Axial coding: Axial coding is the process of relating categories to their sub-categories (Strauss \& Corbin, 1998, p. 123) to create code families. The term axial derives from the fact that coding occurs around the axis of a category, linking categories at the level of properties and dimensions. De Vos et al. (2005, p. 348) define axial coding as a set of procedures whereby data are put back together in new ways after open coding, by making connections between categories. This enabled the researcher to identify the various elements of the process in no particular and logical heuristic relationship. Though open and axial coding are distinct analytic procedures, the researcher alternated between the two when he engaged in analysis.

Selective coding: Selective coding is not very different from axial coding, but takes place at a higher, more abstract level of analysis. De Vos et al. (2005, p. 349) mention that selective coding entails the process of selecting the core categories, systematically relating them to other categories, validating those relationships, and filling in categories that need further refinement and development. These steps are not necessarily taken in linear sequence, nor are they distinct in actual practice (Strauss \& Corbin, 1998)

The researcher performed selective coding and defined the core categories (supercodes) manually, which eventually defined the periods and phases in the integrated storyline of the case.

In summary, the application of grounded theory used in the study is best described by Suddaby (2006, p. 7) 'as a jumble of literature, consultation, data collection, and analysis conducted in ongoing iterations that produce many relatively fuzzy categories that, over time, reduce to fewer, clearer conceptual structures'

Continuous refining of findings: The coding process was aided by the researcher continuously applying a plan, do and review process during the transformation, which mainly involved management, the project team and focus groups. In the coding process this action research element helped to make key decisions about which categories to focus on, where to collect the next iteration of data and, perhaps most importantly, the meaning to be ascribed to units of data' (Burden, 2006, p.31).
Comparison with existing theory: As a final step to provide theoretical legitimacy to transformation as a phenomenon and to help interpret results, the researcher compared this end result with existing theory and contemporary thinking on change and transformation as well as the entrepreneurial organisation.

Definition of the conceptual framework: According to Mouton (2002, p. 195), a typology may be defined as a conceptual framework in which phenomena are classified in terms of characteristics that they have in common with other phenomena. Classification is one of the more basic functions of conceptual frameworks. Based on this definition, the researcher constructed a conceptual framework for a transformational change from a traditionally managed organisation to a successful entrepreneurial unit in a corporate environment. This conceptual framework highlights strategy as a key element, and explains a transformation process that evolves over three distinct periods, with periods one and three manifesting in distinct phases, each with its own unique set of variables in dynamic interaction with one another, contributing to the overall transformational outcome: an entrepreneurial company in a corporate environment.

\section{Strategies used to ensure quality research}

Schurink (2004) contends that there are apparently at least three distinct perspectives on assessing the quality of qualitative research (see Cutliffe, 2000): qualitative and quantitative research should be evaluated by the same measures; qualitative research should be evaluated by standards that have been particularly developed for it; and 'criteriology' (Holloway \& Wheeler, 2002). Lincoln and Guba (1985) developed the concepts of trustworthiness and authenticity as parallel and alternative criteria.

In addition to peer debriefing, to which the researcher has already referred, he also employed member validation or host recognition, authenticity and trustworthiness, credibility, reflectivity, transferability and triangulation to ensure quality research

Member validation or host recognition: According to Schurink (2004), member validation or host recognition entails inviting research participants to comment on the adequacy of the researcher's interpretations, after which said comments are fed back into the research findings. In his initial consulting role, the researcher continuously discussed his developing account of the participants' social construction of the company's transformational process with them, particularly to search for contradictions (see Murphy \& Dingwall, 2003, p. 191).

Authenticity and trustworthiness: These are reflected by 'careful documentation of the process of research and the decisions made along the way' (Daymon \& Holloway, 2002, p. 93). This was done by the researcher. The following criteria are proposed for assessing trustworthiness and authenticity:

Credibility: Schurink (2004) advises that, in order to be credible, a researcher should be able to demonstrate as far as possible what he or she has planned and executed in such a manner that the social construction of the transformation in his or her company could be accurately described. In order to accomplish credibility, the researcher in his role as consultant kept, inter alia, a project journal, or natural history, which enabled him to provide a chronological exposition of the decisions, notably the key decisions, he took during the research.

Reflectivity: For Murphy and Dingwall, (2003), reflectivity constitutes a level of self-conscious reflection on the ways in which the findings of research are inevitably shaped by the research process itself and for an analysis that takes this into account. In his role as consultant, the researcher increasingly realised that he had to foster his capability for reflectivity. As indicated, he kept a project diary in order to engage in self-conscious reflections to assess his impact on the research participants, had regular 


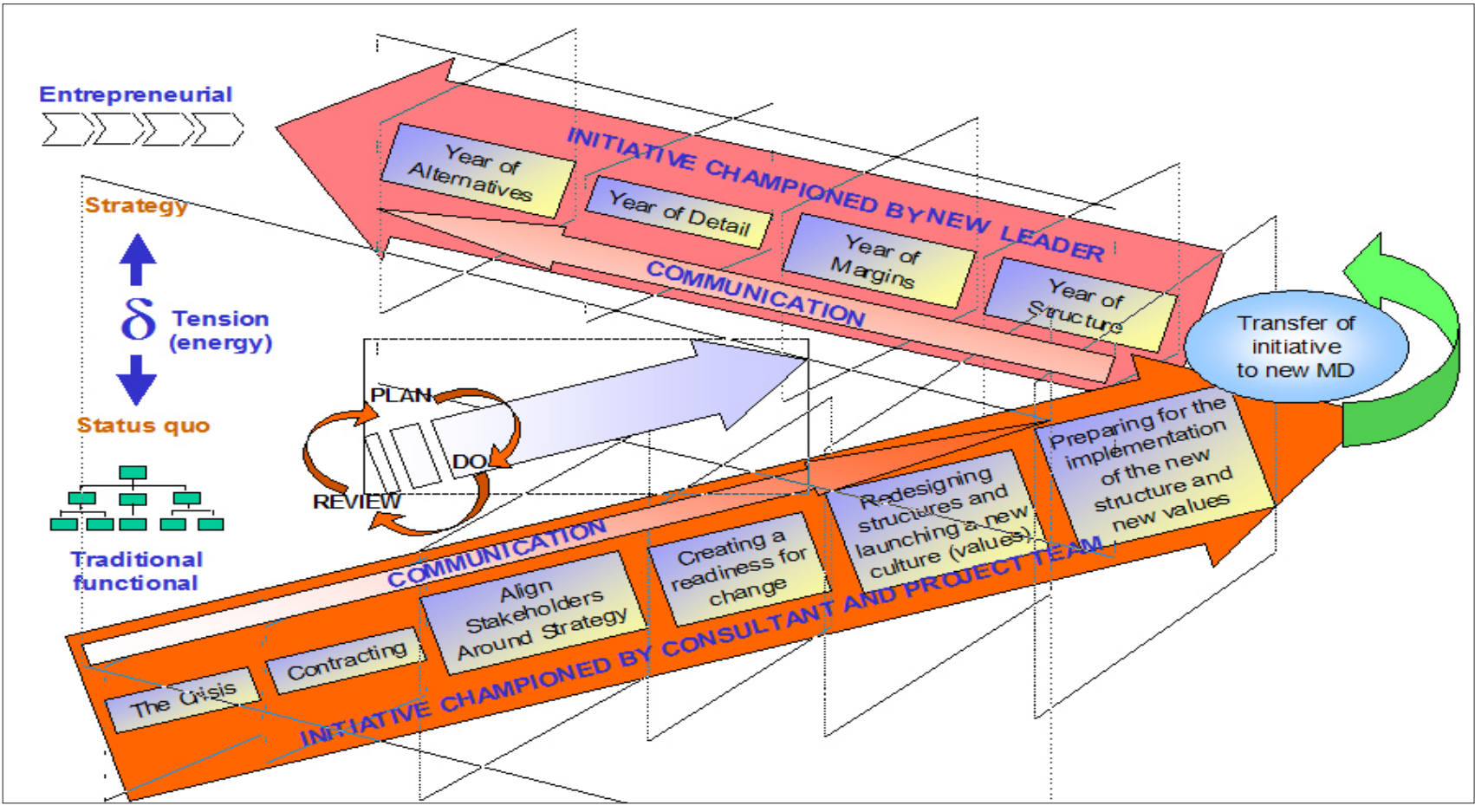

FIGURE 1

A conceptual framework for organisational transformation

discussions with debriefers to create some distance between the research process and himself and, finally, especially during field note compilation, considered possible reasons for the research participants' particular behaviour during the interviews.

\section{Transferability: According to Seale,}

[t]ransferability replaces the notion of external validity or generalisability, and refers to the researcher's task of assisting the reader to transfer research findings of single case studies or smallscale worlds to similar settings.

(Seale, 2000:n.p.)

In the present study the challenge was to unpack the complexity of the transformation process using the consultant paradigm in such a way that it led to the modification and/or improvement of the current practice in the company. Using the scientific paradigm after deciding to engage in the research, the researcher extrapolated his findings as possible guidelines for practitioners engaged in similar transformations in similar organisations.

Triangulation: According to Ritchie and Lewis (2004, p. 43), triangulation involves the use of different methods and sources to check the integrity of or extend inferences drawn from the data. The researcher used different methods and sources to check the integrity of the data and inferences drawn from the data.

\section{Reporting}

It is important for the researcher to explain to the reader what writing style was followed in writing up the study. The writing style that was used to write up this article was mainly the scientific tale. Bruner (1986, cited in Sparks, 2002, p. 31) explains that scientific explanations aim to be formal, logical and, where possible, show mathematical logic. Such explanations are framed to be paradigmatic or logico-scientific in mode of thought.

\section{Ethics}

The authors are aware that the researcher's direct involvement in the case as the consultant, who guided the transformation, could result in a subject-object trap. The researcher admits that his involvement in the planning and deployment of the transformation and his personal relations with the project leader, project members and key staff in particular could have biased his handling of data. As a consultant his past experience of the research variables could have influenced the audit trial. These possibilities cannot be ignored. With this in mind, the researcher remained open to the question of whether these factors were influencing his work or not. Boucher (2003) maintains that selfreflexivity is the key, not whether a researcher holds subjectivist, inter-subjectivist or objectivist assumptions or what theories and methods he uses. The researcher believes he has applied to himself the same rigour of analysis that he applied to those he researched. He furthermore subscribed to the Code of Ethics of the Faculty of Economic and Management Sciences of the University of Pretoria to ensure that sound ethics were adhered to during the duration of the study.

\section{FINDINGS}

The conceptual framework for organisational transformation is presented in Figure 1. This will now be discussed.

\section{Elements of the conceptual framework Strategy}

The transformation was driven by strategy. Strategy provides direction and constitutes the first step in defining the business. Strategy provides cohesion and legitimacy and is composed of a vision, mission, strategic priorities, objectives and values. The vision is essential because it transcends the status quo, providing a link between what is now taking place and what the organisation aspires to build in the future. It creates a healthy tension, positive energy and unlocks essential skills, talents and resources to make it happen. In the company under study, an overall business goal of $15 \%$ earnings before interest and tax (EBIT) to be attained by the end of 2002 was set.

\section{The project team/consultant-championed period}

This alliance championed the transformation process until the start of implementation. It happened by default. A leadership void was created as a result of the resignation of a chief executive officer (CEO), followed by a second CEO who was only appointed in a temporary capacity. A third CEO was appointed, but as a foreigner struggled to establish cohesion within the 
management team. This left the transformation without a proper guiding coalition at executive level, which threatened the credibility of the change effort. The project team/consultant alliance proceeded very cautiously because of tension between the management board and management team, mistrust by lower levels of the change initiative and the radical nature of the transformation - once the intentions became known.

The crisis: Several internal and external factors precipitated the initial crisis, which resulted in the decision to enter into a large scale transformation instead of a process of incremental change.

Contracting: This included the preliminary definition of the problem, exchange of expectations between the major parties and clarification of roles. It also involved building rapport and establishing a working relationship with each key stakeholder.

Aligning stakeholders with strategy: Alignment started with the verification of existing data and reaching a common understanding of the major problem areas. It was recognised that strategy (direction) was the first weakness to be addressed. Two strategic alignment sessions followed, involving the two major stakeholders: the management board and the company's management team. It is important to note that the intent of the strategy was not to design an entrepreneurial organisation (the end state) but rather to create a company that could meet the challenges of the business environment with the necessary innovation, flexibility and resilience. The strategic alignment process also assisted stakeholders to conceptualise the integration of business and transformation, which justified the appointment of a project team.

Creating a readiness for change: Readiness for change involves the correct understanding why change is necessary and establishing a sense of urgency (Kotter 1995). Positive energy has to replace the negative energy that usually characterises a crisis. This phase included the appointment and training of project team members and the drafting of a communication plan, including the official launch. It also saw the introduction of the plan-do-review process, which became a regular feature of the transformation.

Redesigning structures and assessing the culture: This phase started with benchmarking to a sister company in Germany, which had started a transformation more than a year earlier. As stipulated by the strategy, structure became the first focus for change. A new vehicle for strategy was needed. The intent was to design an organisation with the innovation, flexibility and resilience to meet the challenges of the market. It started with an analysis of core processes across the value chain. Simultaneously, simulations were conducted for all leaders, project members and members of focus groups to challenge their paradigms in regard to clients, the business processes, values, structures, authority, team performance and the principles underpinning redesign.

With the help of the project team and focus group members, a first-order redesign was prepared. Core processes now mirrored a value stream that pointed to the client. A guiding coalition was formed between the project team, management team and leaders at lower levels to portray common support for the new structure. The new structure was approved at the November 1998 board meeting and an implementation plan was requested. It was decided that a pilot phase would form the start of the implementation.

Preparing for the implementation of the new structure: Leaders of self-managing teams were appointed and a communication programme was launched that dealt with resistance that now took on new forms. A special task force was appointed to investigate information technology (IT) needs and design an IT system that would augment the new structure. Team leaders were equipped for their new roles.

\section{The period in which the change initiative was transferred to the new managing director}

The leadership void was finally addressed when a new MD was appointed in July 1999 to head the South African operation. His track record was that of an entrepreneurial leader. His style was markedly different from that of his predecessors. He acted like a typical entrepreneurial leader by doing the following:

- He went to Europe and negotiated an agreement with the management board, who gave him autonomy to run the business

- He spent a few weeks studying practices, assessing attitudes and scrutinising the transformation's achievements up to date

- He announced that the strategy, new structure and core values would accommodate all his expectations

- He took accountability for the transformation and in a brilliant political move terminated the project, disbanded the project team and appointed the project leader as his HR manager - thereby reducing the consultant's role to that of a specialist resource

- He added his own branding to the transformation, which included involvement of families in strategy; creating a common vocabulary; emphasising the concept of a global business; removing inconsistencies from the new structure; aligning strategy, structure, discipline and reinforcing implementation as the leaders' responsibility.

This generated much energy at management level and created positive expectations at all levels. People were excited about their new leader and regarded his approach to business as an adventure worthy of engagement.

\section{Phases in the period championed by the leader}

When the transfer was completed, the MD was ready to move resolutely into implementation. It is important to note that he seldom referred to an entrepreneurial unit as the outcome of his efforts; he merely reinforced and adapted strategy, key principles of design and values. In so doing he gave concrete meaning to the original strategic intent: to design an organisation with the innovation, flexibility and resilience to meet market challenges. Four phases in the period championed by the MD crystallised:

- The year of structure (October 1999 to June 2000)

- The year of margins (July 2000 to June 2001)

- The year of detail (July 2001 to June 2002)

- The year of alternatives (July 2002 to June 2003)

Year of structure: He was determined that people should understand the thinking behind the structure and how it worked: A process-driven structure was different from a hierarchical one, and the company's mission was about producing and selling. As part of the implementation of the new structure, he initiated several actions, such as re-employment of secretaries into more meaningful roles; outsourcing non-value-adding functions; retrenching temporary and redundant staff; making computer literacy compulsory for all; encouraging people to make their own decisions; improving the interface with the management board; making teamwork a strategic driver; identifying and developing competencies and reinforcing values as the driver of behaviour. In summary, implementation of the new structure was not only directed at the structure per se, but at the smooth integration of strategy, structure, culture, people, processes and technology across the value chain.

Year of margins: After the implementation of the new structure, the MD became aware of several weaknesses: measurement was inadequate, customer service was poor, knowledge of competitors and forecasting accuracy was lacking and staff did not fully understand the meaning of business and profitmaking. This led to the phase that can be referred to as the year of margins. This involved several actions and brought the company closer to becoming an entrepreneurial unit. These actions included evaluating gross margins and the relationships 
between variable and fixed cost; introducing the War Room and sound measurement; establishing the order book principle building an entrepreneurial culture and launching a companywide incentive scheme and performance-navigation process.

The purpose of the War Room was to reflect the position of the company on a particular day. This required a sound measurement system. The War Room process started with small, informal meetings in each of the business units, followed by a meeting in the War Room. Here information was discussed and integrated by representatives to form a total picture of the company in terms of EBIT and profit/loss on a daily basis. Each person became a generalist who understood all aspects of the operation, grasped the economy in which the business was operating and felt confident to keep the interests of the total company in mind. This also honed their decision-making abilities.

The order book concept offered the MD the opportunity to enter into his coaching role by using discussions regarding the order book to challenge incorrect assumptions and decisions. Errors were used as opportunities to explain business principles. Learning was reinforced by financial management training.

These actions directly contributed to the establishment of an entrepreneurial culture. Staff members became entrepreneurs in both thinking and doing.

To experience risk on a personal level, members of management could place a certain percentage of their salaries on risk. Return of this investment was based on the performance of the company at the end of the financial year, in EBIT terms. Performance was defined as the degree to which the budget was exceeded. The rest of the staff also participated in an incentive scheme, based on performance of the company in EBIT terms.

Year of detail: Relaxed attitudes and an overly confident way of doing things led to short-cuts being taken and facts being generalised.

The MD realised that staff were losing sight of detail - yet detail affected processes, cost, quality, systems, customer requirements, etc. To keep staff alert and focussed, the MD urged them to ask the question, 'What is in the detail?' and encouraged them to challenge measurements.

He introduced a dashboard that created a connection between what every person should measure daily and the company's measurements as a whole. Architecture made provision for indexes varying from financial results to customer value, and from operational excellence to shared learning. On any day of the month the specific position of the company in regard to these indexes was known to everybody. In this way information systems nurtured innovation, encouraging the discussions of innovative ideas on cost reduction and the improvement of processes, products and services (Woodward, 2001). Furthermore, by attending to detail they were rethinking the business and reshaping their own paradigms.

Year of alternatives: On close analysis it can be argued that the first three phases could still be seen as efforts to improve the company's health. The year of alternatives must be viewed as the first of the efforts by the leader to promote growth. This phase involved the following:

- The consideration of alternative products and services, and how they would fit into strategy

- Analysis of inputs to the value chain

- A scan of the total value chain to optimise the entire process This phase resulted in a serious consideration of alternative feedstock sources. On the client-end of the value chain, task forces were formed to attend to new wax applications in cosmetics, health, polishes and emulsions.

\section{Matching the criteria of an entrepreneurial unit in a corporate environment}

The aim of the study was to develop a conceptual framework of events, processes and patterns over the duration of a transformation from a traditional, functionally structured organisation to an entrepreneurial unit within a corporate environment. The remaining question is 'How close did the company come to match the characteristics typical of an entrepreneurial unit?'

In an effort to answer the question whether the company has indeed achieved entrepreneurial status, several criteria were selected, which included inter alia business performance, strategy, structure, the development of new products and markets, the management of risk, the optimisation of systems and the management of human resources.

\section{Business performance}

The linkage between corporate entrepreneurship and a company's performance has been empirically documented in methodologically rigorous research (Covin 1999; Twomey \& Harris, 2000; Zahra, Hayton, Marcel \& O'Neill, 2001). In this particular case, business results over the period 1997 to 2003 reflect a quantum leap. Revenue increased from R442.24 $\mathrm{m}$ in 1997 to R1172.00m in June 2003; EBIT escalated from R3.09 $\mathrm{m}$ in 1997 to R187.70 $\mathrm{m}$ in June 2003. The overall business goal of $15 \%$ nett EBIT was achieved six months ahead of schedule. Despite these impressive results, the company succeeded in maintaining an impeccable safety record.

\section{Strategy}

At the beginning of the transformation, the new strategy and vision guided the thinking. As the transformation progressed, both strategy and vision became more pronounced. Over a fiveyear period the company changed from marketing products to marketing applications, resulting in a market-focused structure, which involved global business units facing the major clients. The strong emphasis on a shared vision, strategy and values allowed leadership to successfully create a purpose, a set of principles to guide the change and a common will (Kuratko \& Welsch, 2001; Scharmer, 2000; Twomey \& Harris, 2000).

The shift from production to marketing was a major change; shifting from the commodity market to the consumer market was a quantum leap. The same could be said for their efforts to apply downward integration into higher-value concepts. They therefore successfully met the challenge to leverage their existing resource advantage (Figueroa \& Conceica, 2000). Their strategy to build people capacity materialised in higher productivity, more staff loyalty and improved results. The majority of the people changed their behaviour (Blumenthal \& Haspeslagh, 1994). The generation of entrepreneurship formed an integral part of a process of continuous strategic renewal (Chakravarthy \& Gargiulo, 1998; Covin \& Miles, 2000). These results are particularly imposing if it is taken into account that new strategic initiatives were engaged without capital investment.

\section{Structure}

The decision to design the company's structure around the value chain was of great significance. It changed the underlying paradigm of employees from a function to the market (Hewson Consulting Group, 2000). A focus on core processes resulted in a structure that was more flexible and adaptable (Echols \& Neck, 1998). Core processes represented a stream of value creation as perceived by the client.

Each value chain was a business unit that added value (Entreplexity, 2002). Technical processes, structures, people, hardware and information systems were aligned to optimise business value chains. Value chains were client-driven and staff members were empowered through membership of self- 
managing teams within business units. They now took full accountability for their own results (Pinchot \& Pinchot, 1993).

The structure therefore correlated with the typical structural characteristics of the entrepreneurial organisation: a business design that faced the client directly, and the use of profit centres and managers in direct contact with the market (Hewson Consulting Group, 2000).

\section{New products and markets}

The company never relied solely on research. They entered new markets, fully utilising existing knowledge within the business units and working diligently to understand these new markets. By understanding these markets and anticipating their reaction, they challenged them and entered them with relative ease. Examples of such new products and markets were:

- Semi-refined wax

- The production of drilling fluids with improved value applications

- Offering a unique raw material to the cosmetic industry

- A mosquito net with a slow-release repellent

- Various products in the health sector

- Fischer - tropsch exfoliating beads.

\section{Managing risk}

The company received a mandate from the management board to introduce new products autonomously (after asking for the mandate). At high risk to themselves, they claimed the mandate to appoint key executives at their own discretion. Discretionary powers in regard to the following were also claimed by the company's leadership:

- To identify new client groups (a regional mandate)

- To update existing products (a board mandate)

- To initiate experimental products (self-claimed)

- To modify product processes (self-claimed).

Risk taking is regarded as a salient quality of the entrepreneurial organisation (Accenture, 2001; Luczkiw, 2002). In this regard management took high risks with the design of the process (value chain)-driven structure, the empowerment of employees at lower levels and the remuneration system. There is also sufficient evidence of high tolerance for risk in markets and with regard to products (e.g. new business in health, cosmetics and candles.) They even took the risk of enforcing discipline in the pricing strategy within the candle industry. Technological changes and outsourcing per se involved a certain level of risk on the part of management. In the same vein procedures, systems and methods, which were promoted at corporate level, were continuously challenged.

\section{Systems optimisation}

Information systems were upgraded, customised and adapted to support structures and aid daily decision making at various levels. Systems were made cost-effective. Twelve days after yearend, the system announced audited results. End-of-the-month results could be predicted with $95 \%$ accuracy. It was evident that the business had succeeded in taking control of IT, while delivering value through the use of technology (Woodward, 2001).

\section{Human resource management}

The management of human resources formed an integral part of the company's strategy formulation and implementation. The HR manager acted as a catalyst on numerous occasions and the HR function served as a powerful link in shaping behaviour, entrenching a new culture and developing the company's ability to be entrepreneurial (Rosner, 2000; Twomey \& Harris, 2000). The HR function played a key role in the development of teams and team leaders. Competencies were assessed and enhanced at every level. Mentorship programmes were successfully introduced and the psychological and personal wellbeing of staff was supported. The company had a powerful training and development policy, and all employees at lower levels met the minimum requirements of the National Qualifications Forum. Several internship and learnership agreements were in place and the company was actively involved in the development of entrepreneurs within the local community.

\section{Culture}

The company's five core values were understood and the associated behaviours were well entrenched. Other characteristics of the culture included ownership of business results, a willingness to take personal accountability, freedom of decision making and discipline at all levels. The five core values and these other work practices were effectively managed to support entrepreneurship throughout the company (Kemolgor, 2002).

\section{Rewards and remuneration}

The company could boast a non-cap incentive scheme, based on EBIT and safety modifiers, which reinforced good performance (Chisholm, 1987; Pinchot \& Pinchot, 1978). Performance-related incentives, measured against EBIT, existed at management levels, thereby decreasing the fixed cost component and increasing the risk component. The soundness of this system was proved by the leaders' decision to discontinue the corporate share option scheme.

\section{Leadership}

The MD's leadership clearly promoted entrepreneurship among people. He was willing to sacrifice control over operational details and showed a keen preference to provide resources instead of giving orders. According to Kemolgor (2002), such practice is a key component in getting people to think differently. His leadership style matched the qualities of transformational leadership as cited by Nanus (1992), Kotter (1995), and Nutt and Backoff (1997).

\section{Performance management}

Business performance formed an integral part of performance management. Scorecards in the business units and self-managing teams were linked to strategic deliverables and were evaluated monthly. Individual performance was measured against business objectives and made provision for assessment of a person's competencies and the degree to which he or she was living up to the company's values. The principle of self-management was nurtured throughout (Chaston, Badger \& Sadler-Smith, 2001).

\section{Sustainability of change}

In September 2003 a climate survey was conducted among a sample of 266 employees ( $82 \%$ of the permanent staff component). The results confirmed the claim that the company had indeed become entrepreneurial and affirmed the sustainability of changes, despite the control and innate bureaucratic attributes of the corporate environment to which the staff had been exposed since January 2002 (when the remaining shares were purchased by the South African owner).

In conclusion, judging by whatever means, there can be little doubt that the transformation to an entrepreneurial company was a success. It is fair to conclude that the company succeeded in regenerating itself (Hamel \& Välikangas, 2003; Scharmer, 2000), qualifying for all four forms of entrepreneurship (Coven \& Miles, 1999): sustained generation, organisation rejuvenation, strategic renewal and domain redefinition.

\section{DISCUSSION}

The authors gained the following insights into organisational transformation:

- Key factors such as strategy, the involvement of large numbers from the workforce, the consolidation of 
structure, appropriate leadership, continuous and wellplanned communication and the role of human resources are significant in transformational change. These factors complement one another, particularly if they are managed in a coordinated manner.

- When an entrepreneurial leader uses his or her positional power in a calculated manner to obtain autonomy for driving a transformation, the resulting dynamics at human level necessitate a substitute leader, acting on an informal level to care for people maintenance.

- A consultant can play a key role in structuring a transformation, obtaining alignment between various stakeholders, facilitating strategic direction, equipping leaders, project members and others for their respective duties during a transformation, etc. Yet, only the leader can implement change successfully.

- Without appropriate and committed leadership who can use positional power to make resources available, reward achievements and establish a culture of discipline, changes in strategy, structures, processes and systems are not sustainable.

- In transformational change the end state evolves as the transformation unfolds. Therefore, the emphasis is more on process than preconceived outcome.

These insights supported the aim of this study, namely to develop a conceptual framework of events, processes and patterns over the duration of a transformation from a traditional, functionally structured organisation to an entrepreneurial unit within a corporate environment.

The authors furthermore discovered the following

- The grounded theory methodology assisted the researcher greatly in making sense of the volumes of data collected over a six-year period and contributed directly to the development of the conceptual framework

- The resourcefulness of surveys during the data-collection and data-verification phases in qualitative research augmented data analysis and contributed to the richness of the overall results of the transformation.

The following limitations were identified:

- Engaging in the roles of consultant and researcher, although not simultaneously, might have resulted in a degree of subjectivity not anticipated and not adequately calculated

- Studying the variables in transformation over a six-year period is complicated by the demands of organisational realities, thereby risking the process of scientific enquiry being obscured.

The following suggestion for further research is made:

- Although the authors are certain that the conceptual framework could be used in other organisations within the manufacturing sector, the applicability of this framework across industries should be studied.

\section{REFERENCES}

Accenture. (2001). Liberating the Entrepreneurial Spirit. Retrieved September 15, 2002, from http://www.accenture.com

Ackerman, L.S. (1986). Development, transition or transformation: The question of change in organizations. OD Practitioner, December, $1-8$.

Babbie, E., \& Mouton, J. (2004). The practice of social research. Oxford: Oxford University Press.

Bamford, J., Ernst, D., \& Fubini, D.G. (2004). Launching a worldclass joint venture. Harvard Business Review, February, 90 100.

Barley, S. (1990). Images of imaging: Notes on doing longitudinal fieldwork. Organisation Science, 1, 220-247.

Blumenthal, B., \& Haspeslagh, P. (1994). Toward a definition of corporate transformation. Sloan Management Review, 35, $101-107$.
Bogdan, R.C., \& Biklen, S.K. (2003). Qualitative research for education: An introduction to theory and methods. (4th edn.). Boston: Pearson Education Group.

Boucher, G.W. (2003). The necessity of including the researcher in one's research. Retrieved January 7, 2003, from http://www. iol.ie/e.mazzoldi/toolsforchange/postmet/research.html

Breakwell, G.M., Hammond, S., \& Fife-Schaw, C. (2000). Research methods in psychology. London: Sage.

Burden F.J. (2006). The development of a South African redesign model - a South African case study. Unpublished doctoral dissertation, University of Johannesburg, Johannesburg, South Africa.

Carlile, P.R., \& Christensen, C.M. (2005). The cycles of theory building in management research. Harvard Business School Division of Research (Working Paper 02 - 016).

Carrero, V., Peiró, J.M., \& Soloman, M. (2000). Studying radical organizational innovation through grounded theory. European Journal of Work and Organizational Psychology, 9, 489-514.

Chakravarthy, B., \& Gargiulo, M. (1998). Maintaining leadership legitimacy in the transition to new organizational forms. Journal of Management Studies, 35(4), 437-456.

Chaston, I., Badger, B., \& Sadler-Smith, E. (2001). Organizational learning: An empirical assessment of process in small U.K. manufacturing firms. Journal of Small Business Management, 39(2), 139-151.

Chisholm, T.A. (1987). Entrepreneurship and bureaucracy. SAM Advanced Management Journal, Summer, 36-40.

Covin, J.G. (1999). Corporate entrepreneurship and the pursuit of competitive advantage. Entrepreneurship: Theory and Practice, 23(3), 47-63.

Cummings, T.G., \& Worley, C.G. (2005). Organisation development and change. (7th edn.). Australia: South-Western College.

Cutliffe, J.R. (2000). Methodological issues in grounded theory. Journal of Advanced Nursing, 31(36), 1476-1485.

Daymon, C., \& Holloway, I. (2002). Qualitative research and marketing communications. London: Routledge.

Denzin, N.K. (1988). Qualitative analysis for social scientists. Contemporary Sociology, 17(3), 430-432.

Denzin, N.K., \& Lincoln, Y.S. (2000). Strategies of inquiry. In N.K. Denzin \& Y.S. Lincoln (Eds.), Handbook of Qualitative Research. Thousand Oaks: Sage.

Denzin, N.K., \& Lincoln, Y.S. (2003). The landscape of qualitative research: Theories and issues. (2nd edn.). London: Sage.

De Vos, A.S., Strydom, H., Fouché, C.B., \& Delport, C.S.L. (2002). Research at Grass Roots: For the social sciences and human service professions. (2nd edn.). Pretoria. Van Schaik Publishers.

Echols, A.E., \& Neck, C.P. (1998). The impact of behaviours and structure on corporate entrepreneurial success. Journal of Managerial Psychology, 13(1/2), 38-47.

Eisenhardt, K.M. (1989). Building theories from case study research. Academy of Management Review, 14, 532-550.

Entreplexity. (2002). Creating an entrepreneurial culture on the edge of order and chaos. Retrieved November 23, 2005, from http:// www.entreplexity.ca/resources/pdfs/entculture

Fernald, L.W., \& Solomon, G.T. (2001). Entrepreneurial leadership: Oxymoron or new paradigm? In D.F. Kuratko \& H.P. Welsch (Eds.), Strategic entrepreneurial growth. Fort Worth: Harcourt College Publishers.

Figueroa, E., \& Conceica, P. (2000). Re-thinking the innovation process in large organizations: A case study of $3 \mathrm{M}$. Journal of Engineering Technology Management, 17, 93-109.

Fisher, S.R., \& White, M.A. (2000). Downsizing a learning organization: Are there hidden costs? Academy of Management Review, 25(1), 224-237.

Franz, D.R., Crawford, D., \& Dwyer, D.J. (1998). Downsizing corporate performance and shareholder wealth. MidAmerican Journal of Business, 13(1), 11-19.

Glaser, B.G. (1978). Theoretical sensitivity: Advances in the methodology of grounded theory. Mill Valley: Sociology Press.

Glaser, B.G., \& Strauss, A.L. (1967). The discovery of grounded theory: Strategies for qualitative research. Chicago: Aldine. 
Greenwood, R., \& Higgens, C.R. (1996), Understanding radical change: Bringing together the old and new institutionalism. Academy of Management Review, 21, 1022-1054.

Guba, E., \& Lincoln, Y. (1994). Competing paradigms in qualitative research. In N.K. Denzin \& T.S. Lincoln (Eds.), Handbook of qualitative research. Thousand Oaks: Sage.

Gummesson, E. (2000). Qualitative methods in management research. (2nd edn.). London: Sage.

Hall, G., Rosenthal, J., \& Wade, J. (1993). How to make reengineering really work. Harvard Business Review, November/December, 119-131.

Hamel, G., \& Välikangas, L. (2003). The quest for resilience. Harvard Business Review, September, 52-63.

Hewson Consulting Group. (2000). Making a compelling business case for CRM. Retrieved November 23, 2005, from http:// whitepapers.zdnet.com

Hill, F.M., \& Collis, L.K. (2000). A descriptive and analytical model of organisational transformation. International Journal of Quality \& Reliability Management, 17(9), 966-983.

Holloway, I., \& Wheeler, S. (2002). Qualitative research in nursing. (2nd edn.). Oxford: Blackwell Science.

Kemolgor, B.H. (2002). A comparative analysis of corporate entrepreneurial orientation between selected firms in the Netherlands and the USA. Entrepreneurship \& Regional Development, 14, 67-87.

Kilmann, R. (1995). A holistic program and critical success factors of corporate transformation. European Management Journal, 13(2), 175-186.

King, W.R. (1997). Organizational transformation. Information Systems Management, Spring, 63-65.

Kotter, J.P. (1995). Leading change: Why transformation efforts fail. Harvard Business Review, March/April, 12-20.

Kuratko, D.F., \& Welsch, H.P. (2001). Strategic entrepreneurial growth. Fort Worth: Harcourt College Publishers.

Lee, P.M. (1997). A comparative analysis of layoff announcements stock price reactions in the United States and Japan. Strategic Management Journal, 18, 879-894.

Lincoln, Y.S., \& Guba, E.G. (1985). Naturalistic inquiry. Beverly Hills: Sage.

Locke, K. (2003). Grounded theory in management research. Thousand Oaks: Sage.

Lowe, A. (1995). Small hotel survival. In B. Glaser (Ed.), Grounded Theory 1984-1994 (pp. 589-612). Mill Valley: Sociology Press.

Luczkiw, E. (2002). Global enterprise: Instilling the spirit. Learning strategies for the new millennium. Retrieved November 23, 2005, from http//.www.cefe.net/forum/Luszkiw.

Mabert, V.A., \& Schmenner, R.W. (1997). Assessing the roller coaster of downsizing. (Business Management), Business Horizons, July/August, 40(4), 45-54.

Maijer, A., Tsui, A., \& Hinings, C. 1993. Configurational approaches to organisational analysis. Academy of Management Journal, 36, 1175-1195.

Marshak, R.J. (1993). Managing the metaphors of change. Organizational Dynamics, 22(1), 44-56.

Miller, D. (1983). The correlates of entrepreneurship in three types of firms. Management Science, 29, 770-791.

Miller, D., \& Friesen, P. (1984). Organisations: A quantum view. Englewood Cliffs: Prentice Hall.

Mouton, J. (2002). Understanding social research. Pretoria: Van Schaik Publishers.

Mouton, J., \& Marais, H.C. (1988). Basic concepts in the methodology of the social sciences. Pretoria: Human Sciences Research Council Press.

Murphy, E., \& Dingwall, R. (2003). Qualitative methods and health policy research. New York: Aldine De Gruyter.

Nanus, B. (1992). Visionary leadership. San Francisco: JosseyBass.

Nohria, N., \& Garcia-Pont, C. (1991). Global strategic linkages and industry structure. Strategic Management Journal, 12, 105-124.

Nutt P., \& Backoff, R. (1997). Facilitating transformational change. Journal of Applied Behavioural Science, 33, 490-508

Patton, M.Q. (1987). How to use qualitative methods in evaluation. Newbury Park: Sage.
Patton, M.Q. (1999). On enhancing the quality and credibility of quantitative analysis. Health Services Research, 34(5), Part 2, December, 1189-1208.

Pettigrew, A.M., Woodman, R.W., \& Cameron, K.M. (2001). Studying organizational change and development: Challenges for future research. The Academy of Management Journal, 44(4), 697-713.

Pinchot, G., \& Pinchot, E.S. (1978). Intra-corporate entrepreneurship. RetrievedSeptember03,2002,fromhttp//www.intrapreneur. com/MainPages/History/IntraCorp.html

Pinchot, G., \& Pinchot, E.S. (1993). How intelligent organizations meet today's challenges. Retrieved November 23, 2005, from http//www.simplerwork.com/library/c10.htm

Porras, J.L., \& Silvers, R.C. (1991). Organizational development and transformation. In M.R. Rosenzweig \& L.W. Porter (Eds.), Annual Review of Psychology, 42, 51-78.

Prahalad, C.K. (1999). Transforming internal governance: The challenge for multinationals. Sloan Management Review, Summer, 5-13.

Price, J.L. (1994). Organisational turnover: An illustration of the grounded theory approach to theory construction. In B. Glaser (Ed.), More grounded theory methodology: A reader (pp. 323-334). Mill Valley: Sociology Press.

Ritchie, J., \& Lewis, J. (2004). Qualitative research practice: A guide for social science students and researchers. London: Sage.

Robbins, S.P. (2003). Organizational Behaviour. (10th edn.). Englewood Cliffs: Prentice-Hall.

Rosner, B. (2000). Nurturing the entrepreneurial spirit. Workforce, 79(10), 96

Scharmer, C.O. (2000, May). Presensing: Learning from the future as it emerges. Paper presented at the Conference on Knowledge and Innovation, Helsinki School of Economics, Finland.

Schurink, W.J. (2004). Qualitative research introducing key features of an interpretative approach to social science research: Lecture Eleven B: Grounded theory [Handout]. Johannesburg, South Africa: University of Johannesburg: PhD in Leadership in Performance and Change.

Schurink, W.J. (2005). Qualitative research design: Part 1 [Handout]. Johannesburg, South Africa: University of Johannesburg: $\mathrm{PhD}$ and MA in Leadership in Performance and Change.

Schurink, W.J. (2007). Qualitative research design: Part 1 [Handout]. Johannesburg, South Africa: University of Johannesburg: $\mathrm{PhD}$ in Leadership in Performance and Change.

Scott, J. (1990). Matter of record: Documentary sources in social research. Cambridge: Polity Press.

Seale, C. (2000). The quality of qualitative research. London: Sage.

Senior, B., \& Fleming, J. (2006). Organizational change. (3rd edn.). Pearson Education: Prentice Hall.

Soy, S.K. (1996). The case study as a research method. Retrieved January 06, 2003, from http://fiat.gslis.utexas.edu/ nssoy/ usesusers/1391d1b.htm

Sparks, A.C. (2002). Telling tales in sport and physical activity: A qualitative journey. Leeds: Human Kinetics.

Stake, R.E. (1995). The art of case research. Newbury Park: Sage.

Strauss, A.L. (1987). Qualitative analysis for social scientists. Cambridge: Cambridge University Press.

Strauss, A., \& Corbin, J. (1990). Basics of qualitative research: Grounded theory and procedures and techniques. London: Sage.

Strauss, A., \& Corbin, J. (1998). Basics of qualitative research: Techniques and procedures for developing grounded theory. (2nd edn.). Thousand Oaks: Sage.

Suddaby, R. (2006). From the editors: What grounded theory is not. Academy of Management Journal, 49(4), 633-642.

Tellis, W. (1997). Application of a case study methodology. The Qualitative Report, 3(3). Retrieved November 22, 2002, from http://www.nova.edu/ssss/QR/QR3-3/tellis2.htm

Thomson, N., \& McNamara, P. (2001). Achieving post-acquisition success: The role of corporate entrepreneurship. Long Range Planning 34, 669-697.

Tuschman, M.L., Newman, W.H., \& Romanelli, E. (1986). Convergence and upheaval: Managing the unsteady pace of organizational evolution. California Management Review, 29(1), 20-44. 
Twomey, D.F., \& Harris, D.L. (2000). From strategy to corporate outcomes: Aligning human resources management systems with entrepreneurial intent. International Journal of Commerce and Management, 10(3/4), 43-56.

US News and Report. (1992). Amputating Assets, 4 May.

Van de Ven, A.H., \& Poole, M.S. (1995). Explaining development and change in organizations. Academy of Management Review, 20, 510-540.

Van de Ven, A.H., Angle, H.L., \& Poole M.S. (1989). Research on the management of innovation: The Minnisota Studies, New York: Bellinger/Harper \& Row.

Van Tonder, C.L. (2004a). The march of time and the "evolution" of change. SA Journal of Industrial Psychology, 30(3), 41-52.

Van Tonder, C.L. (2004b). Organisational change: Theory and practice. Pretoria: Van Schaik.

Van Tonder, C.L. (2004c). "Organisational transformation": Wavering on the edge of transformation. SA Journal of Industrial Psychology, 30(3), 53-64.
Waldersee, R. (1997). Becoming a learning organization: The transformation of the workplace. Journal of Management Development, 16, 262-274.

Woodward, C. (2001). Creating information systems harmony: Challenging old principles of IS governance. CSC Research Services. Retrieved September 10, 2002, from http://www. csc.com/businesstransformation/6.shtml

Yin, R.K. (1984). Case study research: Design and methods. Newbury Park: Sage.

Yin, R.K. (1994). Case study research: Design and methods. (2nd edn.). Thousand Oaks: Sage.

Yin, R. K. (2003). Case study research: Design and methods. (3rd edn., Vol. 5). Thousand Oaks: Sage.

Zahra, S., Hayton, J., Marcel, J., \& O’Neill, H. (2001). Fostering entrepreneurship during international expansion: Managing key challenges. European Management Journal, 19(4), 359-369. 